UDC 621.31:517.938

O.L. Shpak

PJSC “Khmelnitskoblenergo”, 11A Khranovskogo Str., 29016 Khmelnytsky, Ukraine; e-mail: marshall@te.net.ua

\title{
SPEEDED SEARCH OF THE PERIODIC PROCESSES OF DYNAMICAL SYSTEMS
}

\begin{abstract}
О.Л. Шиак. Прискорений пошук періодичних процесів динамічних систем. Моделювання періодичних процесів електромагнітних пристроїв $є$ складною проблемою. Завдання пошуку періодичних розв'язань нелінійних диференціальних рівнянь складніше, ніж задача Коші інтегрування цих рівнянь, оскільки воно накладає на розв'язання умову періодичності, тобто задача стає двоточковою $T$-періодичною крайовою задачею нелінійних диференціальних рівнянь. Мета: Метою роботи $\epsilon$ спрощення методу обчислення елементів матриці чутливості параметрів об'єкта до своїх початкових умов шляхом аналітичного розв'язання рівнянь першої варіації. Матеріали і методи: Пропонується обчислювати елементи матриці моделі чутливості до початкових умов із варіаційних рівнянь не шляхом їх сумісного чисельного інтегрування разом з вихідними рівняннями на періоді, а шукати загальне розв'язання цих рівнянь з використанням перехідної матриці стану. При цьому залишається незмінним порядок рівнянь об'єкта, знімаються обмеження на застосування методу для аналізу складних динамічних систем, значно покращується його ефективність. Результати: Завдяки незалежності диференціальних рівнянь у варіаціях від зовнішнього впливу вони стають однорідною системою лінійних диференціальних рівнянь. Такий підхід суттєво спрощує аналіз і знімає обмеження на застосування методу чутливості до початкових умов при дослідженні динамічних систем будь-якої складності.

Ключові слова: модель чутливості до початкових умов, варіаційні рівняння, періодичний процес.

O.L. Shpak. Speeded search of the periodic processes of dynamical systems. Modelling of periodic processes of electromagnetic devices is a complex problem. The task of finding of periodic solutions of nonlinear differential equations is more complex than the Cauchy task of integrating of these equations because it imposes another condition on the solution - the condition of periodicity, that is it becomes a point-to-point $T$-periodic boundary value problem of nonlinear differential equations. Aim: The aim of the work is to simplify the computing method of the sensitivity matrix elements of the object parameters to their initial conditions by analytical solution of the equations of first variation. Materials and Methods: The author proposed to calculate the matrix elements of the sensitivity model to the initial conditions of the variational equations not through their joint numerical integration with the original equations in the period but to search for the common solution of these equations by means of using a transition state matrix. In this case the order of the equations of the object remains the same, restrictions on the method use for analysis of complex dynamical systems are removed and its efficiency improves significantly. Results: Due to the independence of differential equations in variations from external influence, they become a homogeneous system of linear differential equations. This approach greatly simplifies the analysis and removes the restrictions on the application of the method of sensitivity to initial conditions during the study of dynamical systems of any complexity.

Keywords: sensitivity model to initial conditions, variational equations, periodic process.
\end{abstract}

Introduction. Modelling of periodic processes of electromagnetic devices is a complex problem due to the necessity of taking into account of physical phenomena of different nature - electromagnetic, mechanical, thermal etc. The nonlinearity of the electromagnetic communication of such devices is caused by the desire of maximum use of active materials such as steel of magnetic cores.

Nominal operating modes of the majority of electrical devices are periodic, that is their coordinates (current, tension, interlinkage etc.) are periodic functions of time. The task of finding of periodic solutions of nonlinear differential equations is more complex than the Cauchy task of integrating of these equations from the initial conditions to establishment because it imposes another condition on the solution - the condition of periodicity, that is it becomes a point-to-point $T$-periodic boundary value problem of nonlinear differential equations.

The basic calculation methods of periodic processes of nonlinear systems in time domain are such methods as pseudo viscosity, extrapolation [1], gradient [2] and quasi Newton method, or method which is focused on the definition of the vector of the initial values, corresponding to the established mode of the system.

The pseudo viscosity method comprises an integration of the state equations for many periods, necessary for the damping of transient processes. This approach probably is the best for systems in which the stationary regime is achieved during small number of reaction periods. However, in most 
technical systems the transient process dies during hundreds of periods. In such circumstances, even the use of modern highly effective methods of numerical integration may require large calculating expenses. In addition, the accumulation of numerical integration errors can unacceptably distort the real process; that is evidenced by a large number of practical calculations.

The advantage of the extrapolation method is quadratic convergence and absence of the need to calculate the gradients or the Jacobian matrix. However, this method requires integration of the system of equations for a sufficiently large number of $p+q$ periods. In this case the possibility to find stable and unstable modes is being lost.

The gradient method is based on the mathematical task of optimization of system parameters and the finding of an extremum of the objective function in the presence of restrictions. This method is difficult for the algorithm constructing and is rarely used in practice.

The aim of the work is to simplify the computing method of the sensitivity matrix elements of the object parameters to their initial conditions by analytical solution of the equations of first variation.

Materials and Methods. The author analyses some features of the modelling of periodic processes using the method of sensitivity model to initial conditions. There is a computational complexity of dynamical systems because it is difficult to determine the vector of initial conditions, corresponding to established operation mode.

Let us consider a system of nonlinear differential equations, describing a dynamical system

$$
\frac{d \mathbf{X}}{d t}=\mathbf{A} \cdot \mathbf{X}+\mathbf{B} \cdot \mathbf{U}
$$

where $\mathbf{U}$ - the vector of the input action;

$\mathbf{X}$ - the vector of variables;

A, B - vectors of system parameters.

Periodic solution $\mathbf{X}(t)$ of the system of equations (1), which has period $T$, satisfies the following condition:

$$
\mathbf{X}(t+T)=\mathbf{X}(t)
$$

where $\mathbf{X}(t), \mathbf{X}(T+t)$ - value of the vector of variables at the moments of time $t$ and $T+t$.

The condition (2) turns the task of finding the correct initial conditions into a two-point boundary-value problem, involving a system of nonlinear equations (1), (2). Equation (2) will be written for the initial time $t=0$ as a residual vector, which is called the objective function:

$$
\mathbf{F}(\mathbf{X}(0))=\mathbf{X}(0)-\mathbf{X}(T)=0 .
$$

We must find a solution of system of nonlinear equations (3), in which this vector would be equal to zero. This can be done by using a Newton's iterative method, whereby the initial conditions are specified by the formula at each iteration:

$$
\mathbf{X}^{k+1}(0)=\mathbf{X}^{k}(0)-(1-\mathbf{W})^{-1} \cdot\left(\mathbf{X}^{k}(0)-\mathbf{X}(T)\right),
$$

where $k$ - the index of the Newton iteration, and

$$
\mathbf{W}\left(\mathbf{X}^{k}(0), T\right)=\frac{\partial \mathbf{X}^{k}\left(\mathbf{X}^{k}(0), T\right)}{\partial \mathbf{X}^{k}(0)}
$$

- the matrix of sensitivity of the model variables to their initial values. Each row of this matrix is the gradient of a certain variable in the space of initial conditions, and each its column describes the sensitivity of the entire set of changes of variables to one and the same initial condition. It is obtained by differencing the objective function (3) by $\mathbf{X}(0)$ :

$$
\mathbf{F}^{\prime}(\mathbf{X}(0))=1-\frac{\partial \mathbf{X}(\mathbf{X}(0), T)}{\partial \mathbf{X}(0)}=1-\mathbf{W}=0 .
$$

The initial conditions become the required parameters while solving a system of nonlinear transcendental equations (3).

Previously, the elements of the matrix (5) were calculated using differencing formulas, thus the Cauchy problem was solved (that is a target function $\mathrm{F}$ was being calculated) for one iteration in the total number of $n+1$ times ( $n$ is the order of the system of equations (1)). This method is extremely 
cumbersome and complex, so recently scientists have begun to use the systems of differential equations in variations. They are obtained by differencing the state equations (1) through the vector of initial conditions $\mathbf{X}(0)$. The result is the following:

$$
\frac{d}{d t} \frac{\partial \mathbf{X}(t)}{\partial \mathbf{X}(0)}=\mathbf{A} \cdot \frac{\partial \mathbf{X}(t)}{\partial \mathbf{X}(0)}
$$

or

$$
\frac{d \mathbf{W}}{d t}=\mathbf{A} \cdot \mathbf{W}
$$

In connection with the independence of the vector of input action $\mathbf{U}$ to the initial conditions $\mathbf{X}(0)$ a derivative $\partial \mathbf{U} / \partial \mathbf{X}(0)=0$, and the system of variational equations (7) or (8) is a homogeneous system of linear differential equations.

Traditionally, the system of variational equations (8) is integrated by any numerical method at time interval from 0 to $T$ together with the differential state equations (1), in other words the elements of the sensitivity matrix are searched together with a vector $\mathbf{X}$. Obviously, in this formulation, the order of the initial system of differential equations is doubled, which is a significant disadvantage of the method, particularly in relation to the study of complex dynamical systems.

The ways of problem solving are presented in the article.

The solution of the homogeneous equation (8) can be easily found by a method of separation of variables, whereby the above equation can be written as:

$$
\frac{d \mathbf{W}}{\mathbf{W}}=\mathbf{A} \cdot d t
$$

We get the following equation by integrating the previous one from $t_{0}$ to $t\left(t_{0}\right.$ is the initial time, in particular $t_{0}=0$ )

or

$$
\ln \frac{\mathbf{W}(t)}{\mathbf{W}\left(t_{0}\right)}=\int_{t_{0}}^{t} \mathbf{A}(t) d t
$$

$$
\mathbf{W}(t)=\exp \left[\int_{t_{0}}^{t} \mathbf{A}(t) d t\right] \cdot \mathbf{W}\left(t_{0}\right) .
$$

The condition $\exp \left[\int_{t_{0}}^{t} \mathbf{A}(t) d t\right]$ describes the motion of the system between the moments of times $t$ and $t_{0}$ with zero stimulating effect, and this fact leads to a transition state matrix $\mathbf{\Phi}\left(t, t_{0}\right)$ [4], so

$$
\mathbf{\Phi}\left(t, t_{0}\right)=\exp \left[\int_{t_{0}}^{t} \mathbf{A}(t) d t\right]=\mathbf{X}(t) \cdot \mathbf{X}^{-1}\left(t_{0}\right) \text {. }
$$

It is easy to verify that the transition state matrix has the following two properties:

$$
\begin{gathered}
\text { 1) } \frac{d}{d t}\left[\mathbf{\Phi}\left(t, t_{0}\right)\right]=\mathbf{A}(t) \cdot \mathbf{\Phi}\left(t, t_{0}\right) \\
\text { 2) } \mathbf{\Phi}\left(t_{0}, t_{0}\right)=1 .
\end{gathered}
$$

For a given linear system of differential equations

with a condition

$$
\frac{d \mathbf{W}\left(\mathbf{X}\left(t_{0}\right), t\right)}{d t}=\mathbf{A}(t) \cdot \mathbf{W}\left(\mathbf{X}\left(t_{0}\right), t\right)
$$

$$
\mathbf{W}\left(\mathbf{X}\left(t_{0}\right), t\right)=\mathbf{W}(\mathrm{X}(0), 0)
$$


an unique solution for $\mathbf{W}$ through the matrix $\mathbf{\Phi}\left(t, t_{0}\right)$ will be the following

$$
\mathbf{W}\left(\mathbf{X}\left(t_{0}\right), t\right)=\mathbf{\Phi}\left(t_{0}, t\right) \cdot \mathbf{W}(\mathbf{X}(0), 0),
$$

with all $t$, because

$$
\mathbf{W}\left(\mathbf{X}\left(t_{0}\right), t_{0}\right)=\mathbf{\Phi}\left(t_{0}, t_{0}\right) \cdot \mathbf{W}(\mathbf{X}(0), 0)=1 \cdot \mathbf{W}(\mathbf{X}(0), 0)=\mathbf{W}(\mathbf{X}(0), 0)
$$

and

$$
\frac{d}{d t}\left[\mathbf{W}\left(\mathbf{X}\left(t_{0}\right), t\right)\right]=\frac{d}{d t}\left[\mathbf{\Phi}\left(t_{0}, t\right) \cdot \mathbf{W}(\mathbf{X}(0), 0)\right]=\mathbf{A}(t) \cdot \mathbf{\Phi}\left(t_{0}, t\right) \cdot \mathbf{W}(\mathbf{X}(0), t)=\mathbf{A}(t) \cdot \mathbf{W}(\mathbf{X}(0), t) .
$$

So, the name of the transition matrix of the state is quite suitable for a matrix $\boldsymbol{\Phi}\left(t, t_{0}\right)$, as it reflects the state of the system at the moment $t_{0}$ with the help of a linear transformation:

$$
\mathbf{W}(\mathbf{X}(0), t)=\mathbf{\Phi}\left(t_{0}, t\right) \cdot \mathbf{W}(\mathbf{X}(0), 0) .
$$

Conclusions. The existing practice of investigation of nonlinear dynamical systems by the method of model of sensitivity to initial conditions provides the addition of variational equations of determining the elements of the sensitivity matrix to the original differential equations and general numerical integration of these equations on the period. The growth of the system order of differential equations on the square of order significantly complicates the computational process, narrows down the possibilities and worsens the efficiency of the method.

Due to the independence of differential equations in variations from external influence, they become a homogeneous system of linear differential equations. With the help of the transition matrix of the state it is possible to find the most general solution of this system of equations without joint numerical their integration together with the equations of state and without changing the order of these equations. This approach greatly simplifies the analysis and removes the restrictions on the application of the method of sensitivity to initial conditions during the study of dynamical systems of any complexity.

\section{Література}

1. Skelboe, S. Computation of the periodic steady-state response of nonlinear networks by extrapolation methods / S. Skelboe // IEEE Transactions on Circuits and Systems. - 1980. — Vol. 27, Issue 3. PP. $161-175$.

2. Nakhla, M.S. Determining the periodic response of nonlinear systems by a gradient method / M.S. Nakhla, F.H. Branin Jr. // International Journal of Circuit Theory and Applications. - 1977. Vol. 5, Issue 3. - PP. $255-273$.

3. Aprille, T.J. Steady-state analysis of nonlinear circuits with periodic inputs / T.J. Aprille, T.N. Trick // Proceedings of the IEEE. - 1972. - Vol. 60, Issue 1. - PP. 108 - 114.

4. Kalman, R.E. Topics in mathematical system theory / R.E. Kalman, P.L. Falb, M.A. Arbib. - New Delhi: McGraw-Hill, 1974. — 358 p.

\section{References}

1. Skelboe, S. (1980). Computation of the periodic steady-state response of nonlinear networks by extrapolation methods. IEEE Transactions on Circuits and Systems, 27(3), $161 \quad 175$. DOI:10.1109/TCS.1980.1084794

2. Nakhla, M.S., \& Branin Jr., F.H. (1977). Determining the periodic response of nonlinear systems by a gradient method. International Journal of Circuit Theory and Applications, 5(3), 255 - 273. DOI: $10.1002 /$ cta.4490050307

3. Aprille, T.J., \& Trick, T.N. (1972). Steady-state analysis of nonlinear circuits with periodic inputs. Proceedings of the IEEE, 60(1), 108 - 114. DOI:10.1109/PROC.1972.8563

4. Kalman, R.E., Falb, P.L., \& Arbib, M.A. (1974). Topics in Mathematical System Theory. New Delhi: McGraw-Hill. 